\title{
Intervención en un Hospital Geriátrico
}

\author{
Horacio Foladori Abeledo* - Ricardo Hidalgo Molina
}

\section{Resumen}

El presente trabajo da cuenta de una intervención grupal que el equipo de especialistas realizó en un hospital geriátrico estatal. Se detalla el contrato y el encuadre de trabajo, el desarrollo de la cxperiencia grupal realizada por medio de dos grupos de trabajo sucesivos, asi como las conclusiones diagniósticas y las propuestas formuladas. Se discuten algunos de los problenas de una intervención de esta naturaleza. La técnica utilizada se ubica en el modelo del grupo Balint, el que fue adaptado a las crecunstancias del trabajo. De igual modo, figuran en el marco referencial del equipo de especialistas el grupor operativo de Pichón-Rivière, así como el análisis institucional francés. Se detallan algunas reflexiones.

Palabras claves: analizador, historización, violencia, autogestión.

\section{Summary}

This paper shows a group intervention done by the Staff in a geriatric state hospital. The report includes the contract and the setting, the development of the group experience done through two groups that operate one after the other, and the diagnostical conclusions as well as the propositions presented to the authorities. Also, there is a discussion around some of the problems involved in this lind of incrivention. The technique used was an adaptation of the Balint group, according to the kind of watk wo be icme in the same way, other theorical references are Pichón-Riviere's operative group trame, als will als the frend: institutional analysis. Some considerations are detailed.

Key words: analyzer, historization, violence, autogestion.

\section{Antecedentes}

Las instituciones públicas son portadoras de muchas dificultades y ventajas efecto de la propia estructura del Estado. Ello no significa desconocer la importantísima labor social que cumplen y que no realizan las instituciones privadas por motivos propios de sus intereses. Importa por tanto, y nos importa, el pensar formas en que las instituciones de salud pública puedan resultar tanto en mejores lugares de trabajo para los empleados que laboran en ellas, como también en espacios suficientemente eficientes desde el punto de vista sanitario, ya gue su responsabilidad resulta relevante en lo que al compromiso social se refiere.

El hospital que nos convocó no presentaba ninguna anomalía particular simplemente so trataba de un centro de salud inquieto por pensir algunas dificultades en su funcionanniento; pretendía cambiar algo de su cultura interna y adecuarse

\footnotetext{
"Psicologo, Magister en Ps. Clinica, Dr. en Filosofia, Departamento de Psicologia Universidad de Chile. e-mail dpropsic@abello.tic.uchited

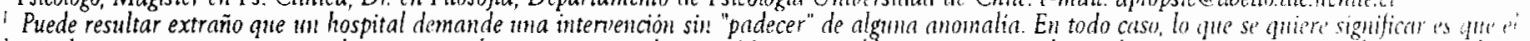

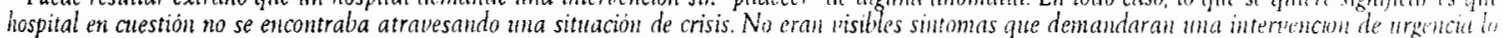

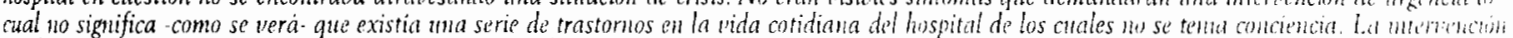

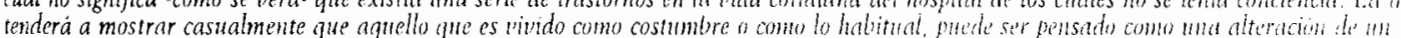
funcionamiento.
} 
paulatinamente a algunos de los cambios que se estaban visualizando en el medio social: mejorar el rendimiento de sus empleados, mejorar la atención a los pacientes y sobre todo convertir al hospital en un lugar un poco más saludable (físico y mentalmente) para trabajar.

Se había realizado ya un primer "diagnóstico" según un análisis FODA que arrojaba los siguientes resultados (se resumen):

"Debilidades:

- Satisfacción personal se constituye en un area crítica: emigración de profesionales, licencias, descontento en el trabajo. Ausencia de espacios para proyectar potencialidades personales. Falta de información.

- Ambiente físico muy precario.

- Clima laboral caracterizado por la mucha dependencia, no existe trabajo en equipo con sentimientos de desconocimiento por el contexto local exterior. Ausencia de liderazgo creativo

- Las relaciones humanas se caracterizan por la falta de confianza.

- La comunicación se reconoce como deficiente, tanto entre el personal como con la familia del paciente. Se señalan algunos puntos criticos : evaluacion y alta.

Fortalezas:

La mayor fortaleza es el capital humeno.

Lealtad de los funcionarios y compromiso con el trabajo, quienes reconocen un deterioro los tres últimos años.

- Conciencia de estar en crisis.

- Se destaca el reconocimiento de los pacientes por el servicio: limpieza, alimentación y buena atención."

\section{Contrato}

Luego de varias entrevistas con el Director de! hospital nos atrevimos a proponer un modelo de funcionamiento que nos permitiera realizar simultáneamente un diagnóstico y una micro intervención, abriendo espacios nuevos y generando un muy incipiente modelo de reflexión sobre el acontecer del hospital. Se propuso entonces trabajar durante 4 meses con dos grupos sucesivos de aproximadamente 12 integrantes cada uno en sesiones semanales de una hora y media. Fllo suponía intervenir sobre el $25 \%$ de los funcionarios de la institución.

El equipo de especialistas dispuso la utilización de la técnica del grupo Balint que provéía de un modelo de intervención psicodinámico, generando la libre asociación focalizada en las vicisitudes del trabajo, privilegiando el intercambio verbal facilitando así la simbolización y la historización de los participantes. También formo parte del marco teórico del equipo ténico el grupo operativo de Pichón-Rivière y los referentes concuptuales y técnicos de intervención instatuciomal desirrollados por la corriente del análisis institucional trances.

El primer grupo seria integrado de manera heterogénea por personal selecconado por la administración de la institución scegun critcrios propios. El segundo quedaria abierto a las condusiones que se pudiesen extraur del primero. La inia condición establecida por el cepupo comsultos consistió en que los grupos fuesen de participación voluntaria. Finalizados ambos grupos, se elaboraria un informe detallado sobre la situación de la institución asi como una serie de propuestas con vistas a profundizar algunas lineas de trabajo, según los objetivos propuestos. Por tanto, esta primera experiencia (piloto) se constituia en un primer momento de un trabajo a largo plazo.

\section{Desarrollo de la Experiencia}

\section{Primer y Segundo Grupo}

El primer grupo, fue constitude por cleccion directa de la administración del hospital an el entendido de que se integraba con el mejor personal, como un modo de premiación y con vistals a reforzar, asimismo, esta actitud de compromiso. $\Lambda$ si, el primer grupo incorporaha un personal rariato a saber: en su mayoria auxiliares adenás de un médico, una asistente social, un kinesiólogo y una nutricionista. Quedo claro de inmediato unal cionta "confusion" entre los integrantes gue no subian si cstaban alli por decisión propia o porcute la institución los habia enviado. En todo caso, fue significativo el sentir de varios de los miembros que manifestaron que si bien originalmente tenian deseos de asistir por propia motivacion, cuandose enteraron de que era "obligatorio" se sintieron tanto decepcionados como molestos por la actitud de la institución que sintieron como autoritaria. Si bien ello podia constituir una fantasia natural en grupos institucionales, la mismat se vio comohorielir an los hechos por una sancion adminismativa yie tue 
aplicada a uno de sus miembros, quien se habia negado a asistir a la primera sesión. Frente a este hecho -el que de algún modo marcó todo el desarrollo del taller- la palabra del equipo de especialistas (realizada tanto en la propuesta presentada como en la consigna de trabajo dada al grupo) quedó invalidada, ya que la estructura institucional decidia, finalmente, acerca de la suerte de los participantes. En este sentido, la expresión espontánea de ideas y sentimientos se vió limitada, la angustia persecutoria se incrementó ya que se sospechaban razones ocultas en este tipo de convocatoria, lo que aumentaba las especulaciones destructivas. Marcado por esto, desde su fundación, el grupo tuvo un desarrollo frenado, cuidadoso al hablar y al analizar sus propias situaciones, con pocos espacios de significativa reflexión acerca del acontecer institucional y de ellos como personal de una institución de servicio. De todos modos, algo siempre se cuela, lo que será comentado en otros parágrafos. Desprovistos los integrantes por parte de la institución del deseo de constituir un grupo y de participar en él, la liberalización de la palabra y por ende del pensar, se vieron reducidas a expresiones esporádicas de algunos miembros. El grupo se movió lentamente, fortaleciendo sus defensas y retroalimentando paranoicamente su proceso. Cabe destacar que el disponer de un espacio (como el que se les brindó) adecuado para verbalizar algunas de estas fantasías, habria ayudado a una paulatina elaboración de la situación critica.

Afortunadamente, esta apreciación evaluativa permitió cambiar radicalmente el enfoque del Equipo técnico para el segundo grupo -aspecto que habia sido previsto por cuanto los grupos habian sido planificados para este efecto, de manera secuencial. El equipo de especialistas redactó un llamado el que fue acogido por la institución que lo difundió, constituyéndose en 15 dias un segundo grupo con caracteristicas sustancialmente diferentes al primero, a saber:

- la mayoria de los integrantes eran del sector administrativo del hospital. ban.

- todos ellos concurrieron porque así lo desea-

- en tanto administrativos, desconocian lo acontecido con el primer grupo lo que de hecho constituia para ellos una experiencial sin antecedentes.

- a su vez, su propia distancia con la problemática de las tareas asistenciales les provera de puntos de vista diferentes y con una adecuada distanciasobre el quehacer asistencial.

- sus mecanismos internos no fiveron alimentados por la paranoia, por el contrario, todos se preocuparon de construir un espacio grupal propio, acogedor y agradable con predominio de una intensión socializadora.

Puede decirse, asimismo que mucho de lo que aqui se expone fue posible por la comparación entre los dos grupos, si bien a mbos operaron de manera dispar, el discurso de cada grupo fue tomado como mostrando los diversos aspectos de la vidia institucional, de sus obstáculoo, de su sentir y de su devenir, - así como de las expectativas de cada uno de los funcionarios que laboran en su interior. Vale decir, lo que alli se hablo es representativo del sentir colectivo. En sintesis, el discurso producido por cada grupo se estructura como las dos carals de una misma moneda. Es interesante a su ve\% descubrir tanto las similitudes como las diferencias thipotetizar en un sentido y en otro acerca de sus causas.

\section{Factores de Análisis}

\section{La problemática del alta}

El alta constituye un indicador privileciado ya que condensa un sinnúmero de efectos y afectos.

Desde un punto de vista teórico se pucde decir que el alta establece el momento de corte, do separación entre el adentro y el afucra institucional. Separacion donde se juega la conclusion de'un proceso y donde se cvalúan los resultados: tanto el paciente como la institución se separan el uno del otro y discriminan cada uno lo propio. Momento de duelo en el que se acepta o no la independencia a partir de la tristeza que implica abandonar lo qu' se tenia. Fil duelo que realizan los fumionarios supone admitir que el paciente "se curó" por lo yue su ayuda ya no es necesaria. Para (1 paciente, el duelo implica tener que reconocer que al hospital

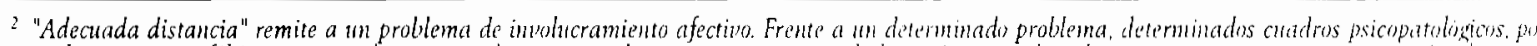

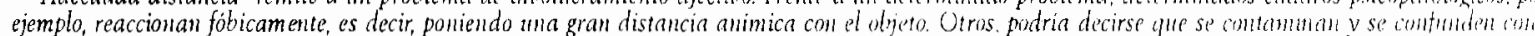

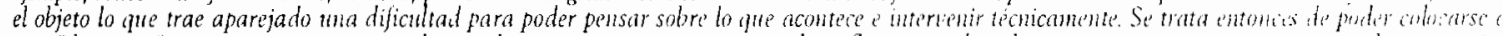

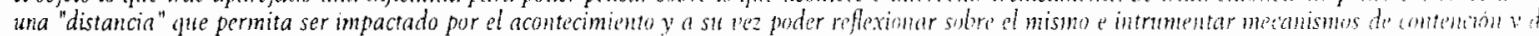
simbolizacion.
} 
no es su casa y que debe hacerse cargo de si mismo de ahora en adelante.

Desde la perspectiva institucional, el alta es el momento en el que se cumple el objetivo y la institución demuestra su eficacia; su existencia queda así justificada.

Pero a su vez, el alta es además importante porque ambos grupos la incluyeron espontaneamente en su discurso, constituyéndose por tanto, en una temática que les preocupa. El tema del alta toca también aspectos que hacen al clima laboral, a la relación entre los funcionarios y a la imagen que la institución tiene de sí misma.

Por ello, es posible afirmar que tal vez sea en el momento del alta donde la institución se juegue su verdadero sentido. En tanto centro asistencial tiene como cometido incidir en un proceso de cura (según los tiempos estipulados para ello)

En algunos casos pareciera que el hospital tiende a convertirse en un asilo. ¿Por qué sucede esto?

Si bien es cierto que hay pacientes cuya polipatologia se traduce en una cura a largo plazo y por la edad de los mismos tienden entonces a morirse en el proceso, hay otros factores que deben tomarse en cuenta: la manera en cómo el grupo humano que labora en el hospital se ubica en su rol, generando un tipo de relación particular que se da en este trabajo con los ancianos. Sugerente es la coincidencia de que los mismos funcionarios (por diversos motivos que no vale la pena mencionar acá) se piensan a sí mismos como en un trabajo para toda la vida. Es decir, los funcionarios no se quieren ir del hospital, no se quieren jubilar, quieren continuar trabajando alli hasta morirse (como siempre, hay excepciones que confirman la regla; por ejemplo, el caso de los individuos que se van a trabajar a otra institución, tema que será considerado más adelante). Esta situación se podría decir que es "contagiosa" y que lleva a que el paciente que ingresa sea visto como alguien que "vicne a quedarse" en lugar de un paciente que debe ser tratado y devuelto a su hogar.

Es cierto que hay una dificultad adicional cuando al paciente es devuelto a su casa, cuando la familia no desea recibirlo: el cuidado de un anciano requiere de tiempo especial, cuidados particulares y erogaciones a veces costosas. Es decir, los funcionarios que dan de alta a un paciente del hospital, se encuentran con una particular resistencia cuando desean reintegrarlo a su núcleo familiar. Sin embargo, esta dificultad no ha sido entrentada romo para ser resuelta positivamente en la mayoria de los casos. Existe en este sentido un "derrotismo" de parte de los funcionarios, cue suponen -muchas veces antes de constatar el hecho- que la familia no desea recibir al paciente dado de alta. Debe mencionarse que esta "complicidad" se asionta en la relación afectiva prolunda que el paciente establece con el personal del hospital -ya por tipo de problema que presenta, va por las condicunes de dependencia en la que muchas vecer semenentra el anciano, hacen que se reprodleca mus fácilmente una relación madre-hijo donde al poco tiempo ninguno de los dos desea separarse del otro. El paciente comienza a acostumbrarse al tipo de trato recibido y el personal identifica con precision la manera en como deben tratar a cada yuien. Y este vínculo se construye entonces como un encadenamiento firme que atenta contra la scparacion encarnada en el alta.

El grupo humano alimenta la idea de que naclie cuida mejor al anciano yue el hospital y a su ver el anciano se gratifica con la idea de que está curindose y que por el motivo de estar enfermo, revib atenciones que no recibiria en su propia casa estando sano. El beneficio es para a mbos por locjue el resultado es la saturación del hospital: son siempre mas los que llegan yue los que se ran. So alimental asi la idea de que del hosprital se sale muerto.

Debe acotarse que la muerte de un anciano tambien tiene el sentido de un fracaso del personal ya que en ese extremo se pierde, alsimismo, el objetivo de la institución que es el le asistir. Por chlo. la muerte del anciano no deja de deprimir custionando la eficacia, la dedicacion, el tuncionamiento del grupo de trabajo y abriendo interrogantes acerca de la autovaloración del personal. Esto explicaria como se verá - una cierta contradicción entre la imagen externa y la inagen interna de la institución.

\section{Historia e historizacion}

Se define como historial la secuencia de hechos que pautan un deteminado acontecer. Parat hospital la historia comenzó hace mucho tiempor. En su edificio se condensa la historia ile lareos anos aunque este hospital se haly (onstiturhe mas recientemente, Rescatar esta historia (la ded dilion, la de otras instituciones y la lul hospital) es 
imprescindible para que pueda ser incorporada por los funcionarios de una manera congruente y ordenada.

Historización es la manera como cada persona y el grupo humano, se cuentan la historia, es decir la interpretación que hacen de los hechos. Esta narrativa, novelada, constituye un punto fundamental de arranque para comprender la identidad del grupo: para el ser humano su "versión" de su historia es un trampolín que lo lanza en su proyecto de vida. Dicho de otro modo, la historización que el grupo que trabaja en el hospital realiza, es fundamental para comprender de qué modo se posiciona del espacio, cuáles son sus proyectos más profundos, así como la manera en que pueden explicarse lo que en su interior acontece.

Ahora bien, resulta que en el trabajo con los funcionarios del hospital se descubre un particular desconocimiento de la historia, lo que repercute en un relato fragmentario y lacunar de los acontecimientos que en el mismo han tenido lugar. En todo caso, se puede ver de qué manera los chismes, los rumores, las anécdotas y comentarios al pasar, sirven para reconstruir una versión necesaria de los hechos pero muy deformada por desconocimiento de las circunstancias en los que los mismos han tenido lugar. Como no se puede vivir sin historia porque ello supondría no tener identidad, el grupo humano "escribe una novela" con los contenidos más disimiles y más contradictorios, lo que causa un efecto de confusión ante la necesidad de tener que asumir nuevas tareas. Por ello, es que pueden surgir proyectos que se distancian significativamente de la historia, generando la idea de que en el hospital se puede hacer casi "cualquier cosa". Las "novelas" institucionales pueden estar alineadas con ciertos hechos, vale decir, los funcionarios podrian contar con aspectos comunes de sus novelas lo que apuntaría a una refundación de la identidad colectiva.

Es oportuno rescatar a través de una pequeña investigación, los rasgos más sobresalientes de la historia y sobre todo difundirla, a los efectos de que su comentario apoye la construcción de una versión más realista y más focalizadora del proyecto del hospital. Y si se tiene en cuenta que el hospital en un futuro mediato se mudará de local, contar con una rica historia que agrupe al personal, será un puntal muy favorable para evitar situaciones que desperfilen su identidad asi como la acción del hospital.
3. Historia personal e historia ad mininistrativa: "El futuro es envejecer".

Trabajar en el hospital es contar con un empleo público, lo que en los hechos significa un empleo de por vida. Y ello no es poca cosa en este modelo económico que se ha caracterizado por introducir la inseguridad entre las personas. Desocupación. privatización del sistema de salud y de prevision, las personas aún no se acostumbran a que no cuenten ahora con lo que contaron buena parte de su vida, sobre todo aquellos que tienen más de 35 años de edad y que vivieron en otra época. Por tanto el empleo hay que cuidarlo.

Pero el empleo no ofrece a la luz del funcionario, estimulos suficientes para volcarse a él de manera creativa y productiva. La falta de incentivos es un denominador común, el escilafón os muy limitado y se requieren muchos años para poder ascender. No hay muchas posibilidades para canbiar de tareas por lo que el trabajo se convierte una cosa muy rutinaria, tediosa, aburrida y poro gratificante. sobre todo cuando todas las semanas hay ancianos que fallecen lo que no deja de deprimir. Esta problemática pudiera ser común a otros espacios de trabajo público. El aliciente de sentir que se construye algo importante y valioso como aspecto significativo de la autoestima- se balancea entre obligaciones más impuestas que asumidas y sensaciones de impotencia tanto frente al trabajo asistencial como ante la burocracia verticalista y formal. En términos generales se puede decir que los funcionarios se sienten no tomados en cuenta en cuanto a proyectos y movi-mientos que la institución debe hacer. Se sienten como obietos que son manipulados por un jugador de ajcdrez, sin entender bien ni los motivos ni las necesidades. Lia capacitación existente no alcanza a cubrir las expectativas ya que si bien hay funcio-narios interesados en mejorar, saben que su apren-dizaje no será considerado ni como posibilidad de ascenso ni en cuanto a otorgarles un trabajo en el que puedan demostrar las virtudes de lo aprendido. Se generaliza asi un estado de apatia protundo que más allá de la buena disposicion momentaneda se revierte en un clima laboral pobre un ideas y en relaciones tensas de trabajo.

Un corolario de lo anterior tiene que ver con la manera en como el grupo de funcionarios interpretal lo que se dice al interior de la institución. ¿Como es que se da la comunicación en la institución? Este aspecto tiene que ver con la necesidad de sociali- 
zación del discurso que se genera en la institución. Hacer del discurso un continuo participativo y democratizado, ayuda a unificar criterios y a definir estrategias y politicas de acción. Actualmente, se puede apreciar que el malentendido cabalga sin freno por el espacio institucional generándose un amplio abanico de respuestas que generan nuevos obstáculos para el trabajo colectivo. Metafóricamente, se podría decir que en la institución resulta dificil descubrir un eje, no porque no haya un discurso hilvanador, sino porque los niveles de comprension y de reformulación del discurso siguen los caminos más dispares.

\section{Institución hacia adentro e institución hacia afuera.}

Se trata de cotejar las imágenes que el hospital genera: hacia el exterior y hacia su interior.

En el primer caso, el hospital resulta un lugar de movimiento: se dictan cursos diversos para especialistas y se entrenan personas en el manejo primario del anciano, se plantean proyectos productivos y se recupera la atención del anciano en los espacios comunitarios. Todo ello, y otras iniciativas se dirigen a posicionar al hospital en un lugar particular, liderando el trabajo con el anciano en el medio. Asi, se ha ganado un reconocimiento público por su labor. Ello no está en duda.

En el otro polo, el hospital supeditado a su vez a una política económica nacional, resulta el lugar de lo estático; a nivel interno el hospital congela a sus funcionarios, bajos salarios, pocas posibilidades de ascenso, carencia de incentivos, trabajo sentido como poco productivo, insatisfacción, ausentismo, etc.; todo lo cual brinda una imagen un tanto gastada y apática de su devenir.

¿Cómo pensar estrategias que relacionen estas dos imágenes tan disociadas? ¿Cómo introducir metodologias y estrategias destinadas a rescatar en lo interno lo externo, como una manera de autovaloración a través de aquellos aspectos más positivos que el hospital presenta? ¿Cómo reconocer en lo externo lo interno, generando condiciones reales desde el afuera, en las que el hospital se ubique de otro modo consigo mismo y con el entomo del Estado?
Hay un punto que es llamativo por los efectos y es el que tiene que ver con el problema de la rotación de personal. Por un lado, el hospital se coloca a la vanguardia nacional en lo que a atención en geriatria se refiere. Así, logra niveles de espccialización alta en su personal profesional. Ha sucedido una y otra vez que dicho personal altamente calificado abandona el hospital para irse a laborar a otros espacios, mejor remunerados. Este "robo" del personal especializado se constituye en una sangría más o menos permanente con el agravante de que en tanto son los mejores elementos los yue se van. dejan tras de si un grupo que -entanto no se puede ir- padece de sentimientos de desvaloriakion. Por otro lado, ha costado muchos ano de wabalu al lograr tales niveles de excelencia por io yuo la merma en la productividad es partudirmente sensible. Agudo problema ya que el modelo socioeconómico dominante legitima el cambio, atribuyéndolo a posibilidades de competir en el mercado., desconociendo a su vez el sentido social de las instituciones en juego. Paralelamente, resulta cn un elemento desmotivante el que parezca clue la institución no puede cuidar a su personal. E! tipo de trato que el personal siente que la institución tiene con él, ¿condicionará de algun modo la manera en como el personal, a su vez se vincula cion los pacientes?

5. Relación de los funcionarios con la institución y con ellos mismos: Algunas características del clima organizacional.

Tal vez haya que tomar como prototípico el inicio del taller: se transcriben las notas tomadas por el equipo luego de la primera sesión del Crupo $A$.

"Llego media hora antes, la Secretaria administrativa desea ir a chequear tocto, aun no sabe an qui sala funcionar. Subimos a un paluellon yue esta vacio: salón amplio, buenal luz, aislado, faltan las sillas. Da orden de que traigan 14 sillas. Le digo que es un buen lugar, mejor que el auditorio. Bajamos. Llega el otro integrante del Equipo y nos vamos para arriba con ella. Cuesta que abandone el lugar. Ante nuestra insistencia lo hace no sin antes manifestar su preocupación por la gente: no se sabe si todos están avisados, de igual modo en cuanto a

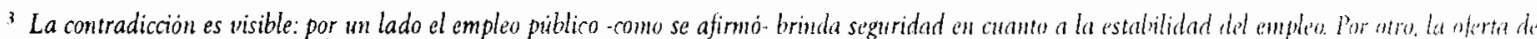

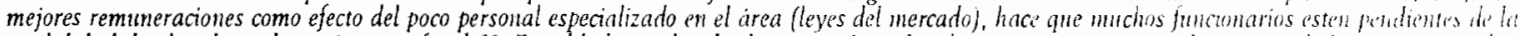

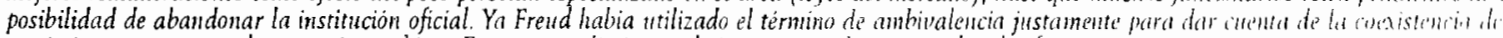
sentimientos opuestos sobre un mismo objeto. Estas contradictiones, olviamente puede ser msualizadas frente a otras sitmacinues.
} 
horario y a lugar.

Comienzan a llegar por goteo, de a uno o de a dos. Esperamos un buen rato. A los 20 minutos la mayoría está presente y podemos comenzar."

Se refleja en lo descrito el siguiente modelo: la institución se preocupa de sus funcionarios de manera burocrática y paternalista, es decir, continuando el movimiento mecánico sin altibajos ni sobresaltos. Nada es más importante que otra cosa en el orden institucional y asi lo sienten los funcionarios. La institución dispone de todo, de manera autocrática:

- dispone del horario (puede organizar actividades fuera del horario y los funcionarios cleben asistir igual)

- dispone del deseo de los funcionarios; es ella que decide si deben o no hacer tal o cual cosa.

- dispone de la vida faniliar de los funcionarios.

- dispone de la calidad del trabajo ya que determina los grados de satisfacción y de frustración de sus funcionarios.

El primer grupo se caracterizó por algunos momentos especiales. La irrupción del taller fue vivida paranoicamente atribuyéndose a los perseguidores las más secretas y dañinas intenciones. Por otra parte, la crisis de un sector produce que el equipo técnico deba hacer una intervención en crisis - lo que no había sido previsto- ya que el enfrentamiento de un sector con la institución podia llevar la "sangre al rio". Esta situación que estalla en ese momento, da cuenta de un nuevo indicador: la crisis. La misma condensa un amplio abanico de sentidos (momento privilegiado de riqueza potencial) entre los que se destaca que el estado de la polarización de impresiones y fuerzas es mayor que lo que la institución está en condiciones de evaluar en cada momento. El "no saber institucional" no es garantia de buen manejo del conflicto. No es aventurado suponer que en otros sectores de la institución hay situaciones similares en gestación, aunque aún no hayan aparecido los sintomas de las mismas.

Un lugar particular lo ocupa la función de asistencia social ya que desde dentro de la institución conecta con el afuera, donde realiza su trabaja Este lugar tiene poca relevancia y aparece institucionalmente como un lugar bloqueado. En todo caso, su liberalización podría re-introducir información fresca, problemáticas desconocidas generando una suerte de re-juvenecimiento de la discusión al interior institucional.
Por último, hay un sector que se ubici en los peldaños más bajos escalafonarios que reaciona un tanto maniacamente ante lo que se vis lumbra como la necesidad de "salvar a la institucion" de la banca rota, o en la terminología neoliberal, de la necesidad de que se autofinancie en todos los sectores. Aprovechan la institución para fantasear proyectos productivos, empresariales y "vender lo que se pueda". Dos vertientes pueden deducirse de lo anterior: 1) El temor al despido que se contrarresta inyectando dincro para garantizar la permanencia en el cargo 2) Generar un proyecto elac interrogue la historia institucional actual on oposicion a la historia desconocida de antano.

Para trabalar con el grupo bi se lispuso un cambio de local (del pabellón al auditoros) lo que no dejo de condicionar tal vez el desarrollo ded grupo. El auditorio aparece como un lugar mas central a la institución, contaminado por ruidos del afuera, pero más fácil de "calentar". Grupo de unal extracción institucional diferente produjo una dinámica más cargada a la necesidad del rescate de la historia del hospital. Su preocupación por la sociabilidad entre sus propios integrantes, d cuidado de unos a otros, y un discurso no exento de agudezas interesantes a la hora de prolundizar en el quehacer institucional, constituyó al gunas de sus cualidades. Pero a su vez, tambicin mostraron aspectos similares al grupo $\mathrm{A}$.

La manera en cóno los funcionarios hablan se condensa en el modelo de La Queja. En ambos grupos, el modelo es el mismo y reiteradamente se puede escuchar como un pensamiento rumiante que plantea sus retlexiones en terminos do una demanda, de un pedido letárgico y halsta cu algunos casos, hipocondriaco. La cueja guarda la luncion de asegurar un cierto ostracismo de lo cotidiance iun particular alejamiento del sutrimiento y del involucramiento. Dado que siempre hay algo do quó quejarse, se cuenta asi con un instrumento que inhabilita, que protege del pensar y' sentir an el "aqui y ahora" institucional y que tácticamente coloca a todos los funcionarios enfrentados con todos los demás. La queja además da cuenta de la impotencia frente a una cotidianeidad que no pregunta y que se impone a pesar de las voluntades personales. Y tal vez, también la queja sea una manera de identificación con los pacientes, ancianos que tienden -en muchos casos- a generar pena. compasión, culpa, como una manera de seducción para lograr mejor trato. La queja nos invita a pensar 
en un estado regresivo más o menos permanente que se caracteriza por culpar al afuera y no hacerse cargo de las propias responsabilidades personales. Son siempre los otros los que no hacen lo que deberian hacer.

La esencia de la queja se define como algo -una falta- que se pide a otro que se haga cargo. Si la falta se asumiera como problema, se vería surgir el deseo de pensar las acciones que tiendan a construir sobre la carencia. La queja muestra entonces una actitud más primitiva. Ahora bien, hay que interrogarse también acerca de las condiciones institucionales que producen la aparición de la queja y no del deseo de construir creativamente.

Por todo ello es que los funcionarios se encuentran en un permanente estado de tensión, ya que sienten que no hay respeto por sus vidas, sus tiempos, sus lugares, sus necesidades. Dicho de otro modo, sienten que la institución los "pasa a llevar" diariamente y en todo momento, sin tener tampoco mucha conciencia de ello; simplemente, la institución lo hace.

Los funcionarios se sienten en términos generales un buen equipo (dentro del cual hay otros subequipos), pero la impresión de que son un buen equipo es más una defensa frente a lo que sienten como una institución avasallante, que como un equipo realmente aceitado en el cual los conflictos que naturalmente surgen se discuten y solucionan. El equipo es el espacio de protección que aunque conflictivo resulta un instrumento útil para defenderse de la institución.

Por otro lado, hay un aspecto muy valioso que tiene que ver con el sacrificio que los funcionarios realizan para sacar algunas tareas adelante. Sacrificio que se manifiesta en el trato entre algunos de ellos y con los pacientes, donde tratan de tapar los "huecos" de la institución con iniciativas personales. Es decir, hacen mucho más de lo que es su responsabilidad. Hay una diferencia entre hacer más y hacer lo distinto, lo creativo; es la distancia entre el trabajo rutinizado y el trabajo nuevo. Tapar los "huecos" implica esforzarse dentro de lo mismo pues lo diferente es visualizado como que la institución no lo autorizaría.

Esto se relaciona con una respetable exigencia a ser mejores y a hacer mejor las cosas, exigencia que muchas veces impide la escucha de las necesidades personales y de la de los pacientes. El discurso en los grupos es inicialmente desde el "deber ser" - seguramente para mostrar ante extraños que conocen el oficio y también para dar cuenta de este "alentarse" permanente que hacen los equipos. Tiempo después pueden comenzar a reconocer algo de la realidad de su trabajo:

- que no "aman" tanto a los ancianos.

- que el trabajo con ellos no siempre es gratificante.

- que es agotador.

- que hay trabajos que son rechazados porque producen repulsa.

- que no conforman un equipo tan concertado y que tienen problemas de responsabilidades.

- que si bien cada quien hace lo que debe, a veces "otros les cargan la mano".

- que se entristecen cuando un inciano muere o cuando no es aceptado en la familia, al ser dado de alta.

- que no le ven muchas perspectivas a su trabajo.

- que la solidaridad entre los funcionarios es cosa del pasado.

En suma, el clima laboral se ve teñido por una suerte de inercia regresivante en la que -por el tipo de trabajo y por las condiciones del mismo- juega un importantísimo papel el moviniento emocional, el que no alcanza a ser contenido por las exigencias del trabajo mismo. Si bien en general se puede afirmar que todo el mundo trahaja mucho, hay factores desgastantes que generan una especit de desubicación con respecto a las responsabiliclades concretas que el trabajo implica. El pensar sobre la tarea ha sido desplazado por el sentir con respecto a los compañeros, constituyendose un ambiunte en el que pesan más las caracteristicas "familiares" que las "laborales".

\section{Propuestas y Conclusiones}

Por lo ya senalado, corresponde claborar un proyecto que vaya transitando hacia una institución un poco más sana. No es mucho lo yue hay yue hacer, si bien se considera que debe ser realizado de manera planificada y ordenadat.

\section{El rescate de la historia.}

Es importante, como ya se señaló, que el personal pueda contar con datos ciertos de lo que fue el local, quienes pasaron por alli y que huclla

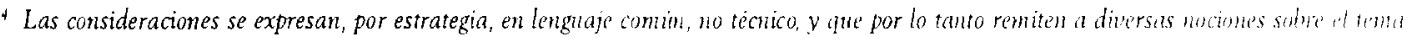


dejaron, qué instituciones, en qué fechas y qué hicieron, acontecimientos, anécdotas, etc.

Esta tarea de recopilación histórica puede ser desempeñada por algún especialista que vaya agrupando los datos fragmentarios de la historia de la institución, de manera organizada y coherente, para ponerlos periódicamente a disposición del personal. Es parte del reservorio de la cultura institucional (énfasis en la identidad colectiva).

\section{El rescate del lugar institucional de la} función de asistencia social como la ventana que conecta con un afuera que enriquece y desafía a adecuarse a él.

La función podria ser pensada más allá de los parámetros del trabajo rutinario, vale decir, diagramar una estrategia de trabajo con los familiares de los pacientes y con otras instituciones de acogida, que posibilite la reinserción social del paciente de alta.

Acá se abren las posibilidades de un nuevo trabajo que es el que debe realizarse con las familias de los pacientes y que trasciende la función del asistente social. La reinserción del anciano en la familia toca aspectos sociales, pero también otros psicológicos que hacen a la valoración familiar del lugar del anciano, a su función en la familia y a la dinámica particular de ésta. Para ello, se podría pensar en recurrir a un psicólogo especializado en el trabajo grupal familiar ( énfasis en el lugar social de la institución).

\section{Políticas con el personal.}

Se sugiere desarrollar varias acciones paralelas:

- Trabajar sobre la información interna de la institución :

Reuniones no autoritarias de discusión de problemas y de politicas (énfasis en el pensar).

Generar espacios de intervención y de propuestas que puedan ser llevadas a cabo (énfasis en la participación).

Rescatar la escucha del discurso institucional (énfasis en la valoración personal).

- Elaborar un programa de incentivos (económicos y de otras clases) (énfasis en la motivación).

- Trabajar sobre un escalafón posible: muchas veces importa más el sentido moral del ascenso que el estímulo económico real (énfasis en el reconocimiento)

- Atentar contra los feudos laborales, rotar al personal en la medida de lo posible (énfasis en una visión global del trabajo).

- Recuperar el curriculum real y personal de las potencialidades de los funcionarios, para que las cualidades personales puedan ser reutilizadas en el marco del quehacer institucional (énfasis en la contribución personal).

4. Rescatar determinados espacios de sociabilidad entre los funcionarios.

A saber: celebraciones, eventos culturales y jornadas especiales, en los que los funcionarios puedan recuperar el intercambio entre ellos incluso como espacio lúdico-productivo que ayude a su vez a liberar tensiones que el trabajo produce y a generar redes de apoyo para ellos mismos (énfasis en la solidaridad).

\section{Introducción de la visita del Director.}

De manera periódica y fiscalizadora. La Dirección se entera asi directamente de lo que acontece en los pabellones y con los diversos pacientes. Fortalecer así la línea del trabajo interno y combatir la queja. La visita requiere de la asistencia de todo el personal del pabellón, por lo que se constituye en un lugar privilegiado de intercambio y de democratización del trabajo ya que todos serán escuchados y deberán dar cuenta de sus responsabilidades (énfasis en el orden institucional y en la responsabilidad del trabajo).

6. Introducción de las reuniones de equipo.

Por pabellón, de manera periódica, donde se incorpore todo el personal que atiende a cada paciente para que el médico que las encabece escuche a todo aquel que tenga algo que decir sobre el paciente.

Nuevamente se trata de rescatar el espacio de trabajo de manera racional pero donde los afectos puedan ser también escuchados. Pero el asunto va más allá, porque el espacio para generar las posibilidades de la escucha implica que todos los participantes tienen algo que decir sobre los pacientes y ello es parte del "saber" sobre el anciano. Se trata de complementar el "saber médico" con el "saber" de los otros integrantes del equipo asistencial del pabellón, es decir, integrar todo el "saber" sobre el caso, para ponerlo al servicio de la cura, que daría mayor coherencia al proyecto terapéutico (énfasis en el trabajo en equipo ). 


\section{Acciones del Equipo de Expertos}

Desde la perspectiva del Equipo de expertos en procesos grupales, y a los efectos de continuar con la planeación, objetivos y metas definidos en la propuesta inicial, se propone desarrollar las siguientes acciones:

Las siguientes propuestas que emanan de un Diagnóstico Institucional global, se articulan y apoyan mutuamente como un todo, en tanto están diseñadas cuidadosamente para combinar tanto las acciones sobre los ancianos mismos como aquellas que operan como apoyo institucional periférico.

1. Que las reuniones de equipo por pabellón sẹan coordinadas por un especialista de manera de garantizar que la Escucha pueda ser ampliada y de que todos los que de un modo u otro participan en el proceso de rehabilitación del anciano, puedan expresar su pensar y sentir sobre el particular (se trabajaría en base a lo señalado en el punto 6 anterior.)

2. Generar un Taller de 2 horas de duración por mes, abierto a todo funcionario de la institución con el propósito de producir el efecto de la recuperación de la palabra sobre temas vitales para la institución y posicionamiento que favorezca los procesos de identificación con la institución, coordinado por dos especialistas.

Ambas acciones van dirigidas a estudiar la latencia institucional que se mueve al interior de los grupos y producir los espacios en los que sea posible desplegar un pensar sobre la problemática del poder en todos los órdenes institucionales, como una manera de descubrir sentidos en los fenómenos que se producen.

\section{Algunas reflexiones sobre este primer momento}

El trabajo que nos convoca presenta una serie de aristas que ayudan a hilvanar un ordenamiento de las reflexiones. Sin pretender ser exhaustivos, se pueden elegir algunos tópicos sensibles y relevantes en la problemática descrita.

1. El problema de la salud mental de los funcionarios.

A partir de lo señalado en esta intervención, una de las primera reflexiones que podrian realizarse tendria que ver con las posibilidades de salud mental del personal y la manera en que la misma afecta el desarrollo del trabajo asistencial que se realiza con los pacientes internados. Es dificil escapar a considerar los requisitos de ingreso para laborar en un lugar de estas caracteristicas, como enfatizando, por ejemplo, el papel que puede o debería cumplir el proceso de selección de los funcionarios. Y sobre todo cuando uno se entera de que algunas veces los funcionarios son enviados desde otros servicios "como castigo", vale decir, como una suerte de proceso punitivo por supuestas o demostradas fallas en otros servicios. Issta acción se realiza con la intención de establecer el lugar del ostracismo laboral y social en un servicio que se centra, casualmente, en la atención de aquellos que ya no son útiles desde la perspectiva de la producción. ¿Coincidencia de enfoques? ¿Casualidad inimaginable? Lo cierto es que la etiquetil se sostiene al igual que en otras instituciones que terminan produciendo aquello que dicen combatir.

Puede pensarse que todo el personal está sometido a una situación tan estresante que seria necesario e imprescindible que semanalmente contaran con espacios catártico-terape uticos que los ayude a elaborar las ansiedades yue ol trabajo y la jubilación produce. Escierto yue esta poudrai ser un a recomendación, si bien habria que interrogars. acerca de su eficacia, más allá de las posibilidides reales para contar con un scrvicio addicionial de esta naturaleza.

¿Es acaso la psicoterapia el instrumento más adecuado a utilizar en esta situacion o es posible pensar desde otros parámetros el probloma de lia salud mental pública de los funcionarios? ¿De qué manera lo que llamamos habitualmente salud mental no aparece definido desde determinados criterios conductuales, los que a su vez son fijatos desde precisos lugares sociales? En suma, al hospital como institución ¿Cuental con las condiciones necesarias paraque el espacio (en téminos de silud mental) sea promotor y garantice lat silud al sus agentes, o en realidad se convierte 'n un "foco de infección y de contagio" - para utilizar una tominologia médica no del todo feliz-donde la patología personal de los participantes se ve agrilviala mis que neutralizada? Ya hace años, Bleger sunalaba para al caso de los maniconios yue los mismos, lepos de discriminarse del objeto de su existencia - - lol locoutilizaban la lógica de este en su fumcionamurento 
institucional, con lo cual en vez de constituirse en lugares donde se combatia la locura, en los hechos se la generaba.

Y por último, iqué hacer con la depresión "enquistada" que identifica una singular aspiración que pone en igual plano tanto a pacientes como a funcionarios: ambos deben salir de la institución... muertos?

\section{El problema de la violencia en el hospital geriátrico}

Pensar sobre la violencia en el hospital significa articular una serie de planos de análisis de la cotidianeidad que ocurre en su interior:

Un primer nivel de análisis tendria que ver con la violencia que se ejerce por medio de una estructura disfuncional al tipo de paciente que reune: una arquitectura no adecuada a las condiciones de posibilidad de un cuerpo que no puede adaptarse al marco exterior. Escaleras, temperatura del local, espacio personal en el que los objetos queridos no siempre pueden estar al alcance de la mano, manejo particular de la intimidad donde la humillación puede ser la manifestación más común, falta de resguardo a las miradas de otros asi como la designación del paciente por su patologia en lugar de por su nombre.

Otro lugar lo ocupa el de la rigidez institucional: cuanto más "científica" la institución, más "preocupada" por los procedimientos administrativos, los que a su vez desafectivizan el trato con los pacientes. En este abanico, por ejemplo, las casas de reposo figuran con un relajamiento casi total de las normas. Dicho de otro modo, las instituciones se mueven entre márgenes, cuyos extremos -por exceso o por defecto- son productoras de situaciones cercanas al destrato personal.

No hay que descuidar la cuota de violencia que corresponde a los mismos pacientes, los que a su vez son portadores (por sus antecedentes, por su patología, por su historia) de diversos grados de hostilidad que puede manifestarse o desencadenarse en la situación de internación. Las polipatologias incluyen trastornos que afectan las relaciones interpersonales o las relaciones consigo mismo. Es importante considerar el vinculo del anciano con el equipo médico como totalidad, ya que muchas veces el paciente puede intentar acciones divisionistas para obtener puntuales beneficios. Es observable que estos comportamientos ocurren ante la falta de provecto terapentico, ausencia de personal auxiliar o de entermeria con quien el fordent pudiera tener una relacion mas ceranda, conticion latentes al interior del equipo y sobri todo en periodos de crisis o de cambios sustantwos a nivel institucional.

El tema de la violencia en la institución adquiere su manifestación visible frente al maltrato al anciano, sintoma que condensa algunos de los aspectos señalados y otros que se indicarán a continuación.

El maltrato se constituye en un nodulo que abrocha una amplia gama de tematicas y se convierte -por sus implicancias- en un espacio mudo: al estar manifiestamente penalizado no es posible hablarlo y, por ende reconocerlo en la situdción de trabajo grupal, y sin embargo se constituye en una especie de napa que se desplaza clandestinamente en toda temática tratada.

Si bien durante las sesiones no existieron de hecho manifestaciones ni alusiones sobre el tema, la institución sabe que el maltrato al anciano es un hecho de la cotidianeidad del hospital; difícil de cuantificar, pero no dificil de detectar en el trato personal, grupal e institucional del personal con los pacientes. Las formas que este maltrato adyuicr abarcan una amplia gama de manifestaciones y reacciones -más allá de las señalidas anteriomenteque van desde el insulto manifiesto hasta otros mas o menos velados, desde la intervención verbal agresiva hasta formas de contacto corporal donde se nota la intención hostil física o también a traves de la ausencia de respuesta, de servicio, de atención, o la postergación más o menos indefinida de la presencia del personal. No olvidarse de que toda intervención física puede ser realizada de manera más o monos agresiva, desde tomar la presion o cambiar de posición al anciano. Tambicn se incluyein en el maltrato las amenazas del tipo "si no hace tal cosa lo voy a soltar" o "si no se apura lo dejor así nomás". Por último, hay un tipo de maltrato yue se origina en una suerte de venganza personal y colectiva y que adquiere todas las caracteristicas reconocidas las distancias- de los fenomenos de linchamientos colectivos: hay ancianos yue por su patologia y por las característicals de su personalidad, se constituyen en los sujetos odiados por todo el personal, ancianos que se convierten fácilmente en chivos expiatorios de la incapacidad y la frustración de la pirámide asistencial, desde al médico hasta el último de los auxiliares. Ancianos que son 
contestadores, criticones y encuentran todo mal y a su vez se pasan solicitando atención todo el día; ancianos que todo el personal desea sacárselo de encima lo antes posible, incluso precipitando el alta y forzando de algún modo la voluntad del anciano a no retirarse del hospital hasta con la fuerza pública.

Ahora bien, es cierto que estas conductas pueden ser sumariadas y que existe una preocupación de la institución sobre el particular que conlleva a la implementación de medidas que puedan neutralizarlas y sin embargo es claro también que las determinaciones estructurales harán que, de un modo u otro, siempre existan. No solamente porque la presencia de pulsiones agresivas es constitutiva del ser humano sino porque además hay otros planos de análisis social en los que el maltrato se constituye como un elemento fundante.

A través del análisis realizado de la situación de los funcionarios queda patente las diversas formas en que la institución y por ende el Estacto, maltrata al personal; por ejemplo, cuando dispone de traslados sin consulta, cuando ignora capacidades o iniciativas, cuando frustra expectativas y congela ascensos, cuando dispone de los horarios, cuando dispone de los feriados y días de descanso, cuando sanciona de manera arbitraria ignorando su propio discurso, cuando no informa adecuadamente de sus proyectos e iniciativas, cuando supone que el funcionario no siente y no piensa, cuando se congelan salarios y/o se los mantiene tan bajos que la gente no puede vivir con lo que gana, cuando transforma los beneficios sociales en un problema de capital privado, cuando elimina la cobertura en salud y en educación generando nuevos focos de intranquilidad colectiva y social, cuando trata a todo ser humano como mercancía..

Entonces aparece en toda su magnitud el doble discurso de la institución: el problema es el maltrato al anciano; cuando del personal se trata es porque operan las leyes del mercado. Pero a su vez la institución en tanto debe negar el maltrato a sus funcionarios, se preocupa por el maltrato al anciano.

Este punto nos lleva invariablemente al siguiente.

3. El problema de la gestión; en especial, de la autogestión

Los procesos de descentralización administra- tiva, de modernización de la gestión publica suponen -al menos en los discursos- un mayor grado de participación en las decisiones, niveles de coresponsabilidad, incremento de la eficiencia en virtud de mejores relaciones laborales que aumenten los grados de compromiso con la gestión, estudio de iniciativas -que en principio son bien recibidas-, etc. El fortalecimiento do las relaciones laborales y de la relación con un trábajo más ricoy productivo repercutiría en un aumento de los niveles de satisfacción personal. lil entrenamiento, la educación, la salud, pasan a constituir parte del "capital" que la institución debe cuidar.

En tos hechos las cosas no ocurren tan facilmente. La presencia de controles admmistrativos por doquier, el centralismo en la disponibilidad presupuestaria, la estructura laboral organizada de manera piramidal y fuertemente jerarouizada, la distribución del personal por funcioncs y por zonas, etc., convierten a und institucion en un monolito con pocas o nulas posibilidades de Hexibilización.

Vale decir, ha primado claramente lo instituido por sobre lo instituyente y la conflictiva del poler se ha orientado más a mantener lo existente que a la posibilidad de gestionar lo nuevo. Cocxisten, por tanto, normativas no coherentes entre si, yue a su vez se apoyan en los naturales temores ante lo nuevo. Y si bien es cierto que la institución deberá flexibilizarse para poder ajustarse a nuevas realidades no es menos evidente que la flexilibización en los hechos, no se desarrolla por los caminos previstos en sus propuestas innovadoras.

El funcionario, entonces, no deja de permanecer perplejo en tanto es atravesado por una normativa contradictoria y por discursos plagados de dobles mensajes que lo dejan como inmóvil, entre la espada y la pared:

- Capacitate pero no apliques lo que aprendas.

- Participa pero no te organices.

- Hazte cargo responsablemente de tu trabajo pero no dispongas de tu horario.

- Atiende bien al anciano pero no te quejes si la institución te maltrita a ti.

- Debes estar a gusto en la institucion alunque la misma se olvide de ti.

- No debes pensar mal de las autoridades: toda medida que se ha adoptado ha sido realizada para beneficio de tí y de la institución.

- No puedes destallecer en tu trabajo, la institucion te necesita aunque te pague bajos salarios y no reconozca tu labor. 
Ahora bien, este no es un problema de las autoridades de turno, ni siquiera de la cúpula ministerial. Tiene que ver con la estructura general del Estado, con la manera en cómo la institución se sostiene y visualiza las posibilidades de sus cambios. Hasta dónde el entramado normativo social autoriza vías alternativas. $Y$ no es por falta de energía ya que las posibilidades son enormes; prueba de ello es la manera en como el personal es capaz de intervenir en situaciones de crisis, de participar creativamente y resolver encrucijadas, pero siempre bajo la marca de un espacio no normado, como si la legalidad imperante limitara incluso la posibilidad del pensamiento.

¿Cuáles son los niveles de socialización de la información que se requieren para que la gestión (co-gestión, autogestión) sea posible? ¿De qué modo la estructura piramidal que respeta y congela los roles fijos por funciones, atenta directamente contra los intercambios interpersonales limitando las posibilidades reales de pensar con el otro? ¿Es posible en la órbita del Estado el pensar en procesos de re-ingeniería, sobre todo cuando hay una enorme experiencia acumulada que no se materializa en maquinaria sino en un saber colectivo asentado mal o bien en equipos de trabajo? ¿Hasta que punto es posible recortar el espacio de trabajo y "aislarlo" del exterior institucional como para que el trabajo en si pueda recuperar sus condiciones satisfactorias para beneficio de los funcionarios y por ende de los ancianos que requieren del servicio?

\section{Referencias}

Anzieu, Didier y otros. (1978). El trabajo psicoanalítico en los grupos, S. XXI, México.

Anzieu, Didier. (1986). El grupo y el inconsciente, Bib. Nueva, Madrid.

Balint, Michacl. (1961). El médico, su paciente y la enfermeded, Ed. Libros Básicos, Buenos Aires.

Balint, M. y E. (1984). La capacitación psicológica del médico, Gedisa, Barcelona.

Balint, E. y Norell, J. S. (1979). Seis minutos para el paciente, Paidós, Buenos Aires.

Baremblitt, Gregorio y otros. (1991). El espacio institucional $\mathrm{N}^{\circ}$ l, Lugar Editorial, B.A.

Bauleo, Armando y otros. (1983). La propuesta grupal, Folios, México.
Bauleo, Armando y otros (1990). La concepcien operalned de grapo, Asoc: Española de Neuropsiquiatria, Watrod

Castoriadis, Cornelius. (1983). La instifucion imeginama de la sociedad, Vol. 1 y 2, Tusquets, Barcciona.

Foladori, Horacio. (1992). Del desen a la autugestion, Tramas, UAM-X, Mixico

Foladori, Horacio. (19)3). El grnpo ancilisis tecnica de diaunostico de clima organizacional, Revista P'sicolowia, Vol. IV. i. de Chile, Santiag(2.

Foladori, Horacio. (19)4). La solud de la institucime. Hiria, Ano 2. $N^{\prime \prime} 3$, Santiago

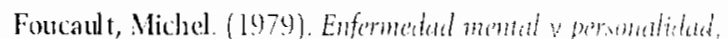
Paidós, Bucness Aires.

Guattari, Felix. (1976). Psicuanilisis y trominersodetert. S XXI. Buenos Aires.

Guatari, Felix y otros. (1981). La internencion instincional, Folios, Mexicu.

Kaës, René y otros (1982). Le travail psyclumalytique doms les groupes, Dunod, Paris.

Kaës, Rene y otros. (1989). La institucim v las instituciones. Paidós, Buenos Aires.

Kaës, René. (1905). El grupo y el sujeto del gnapa, Amurrortu, Buenos Arres.

Kononowich, Bernardo y Saidon, Osvaldo. (199!) ] La escence institucional, Lugar Editorial, Buenos Aires.

Lapassade, George y otros. (1977). El cmálisis institucional, Campo alyierto, Madrid

Lourau, René. (1975). El ancilisis institucional, Amorrortu, Ruenos Aires.

Lourau, René (1980). El Estado y el mansciente, Kairus, Barcelona.

luchina, Isaar. (1982). El gnupo Bolint, Paidion, Buenun Aires.

Mendel, Gérard (1974). Sociopsicoancilisis N" ] ? ?

Amorrortu, Bunenos Aires.

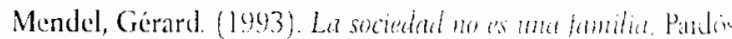
Buenes Aires

Pichón-Rivière, Enrique (1975). El proceso granpal, Niseria Vision, Buenos Aires

"Roche", Laboratorio. Balint Vol. I y II, Francia (tollec(u) 